\title{
Effect of platelet-rich plasma on postoperative peritoneal inflammation and adhesions
}

\author{
Dursun Özgür Karakaş¹, Özgür Dandin², Tuba Müftüoğlu³ , Deniz Tihan ${ }^{4}$, Ahmet Selim Bal5, \\ Şükrü Yıldırım
}

\author{
${ }^{1}$ Department of General Surgery, Okmeydanı Training and Research Hospital, Istanbul, \\ Turkey \\ 2Department of General Surgery, Trabzon Training and Research Hospital, Trabzon, Turkey \\ ${ }^{3}$ Department of Biochemistry, Sultan Abdülhamid Han Training and Research \\ Hospital, İstanbul, Turkey \\ ${ }^{4}$ Department of General Surgery, Sevket Yılmaz Training and Research Hospital, \\ Bursa, Turkey \\ ${ }^{5}$ Department of Clinical Biochemistry, Faculty of Medicine, Uludag University, Bursa, Turkey \\ ${ }^{6}$ Department of Pathology, Faculty of Medicine, Maltepe University, Istanbul, Turkey
}

Submitted: 28 May 2018; accepted: 27 October 2018

Online publication: 18 April 2020

Arch Med Sci 2021; 17 (5): 1408-1413

DOI: https://doi.org/10.5114/aoms.2020.94538

Copyright $\odot 2020$ Termedia \& Banach

\begin{abstract}
Introduction: Postoperative peritoneal adhesion is an important complication of abdominopelvic surgery. The aim of this study is to reveal the effect of platelet-rich plasma (PRP) on postoperative intraperitoneal inflammation and adhesions.

Material and methods: Twenty-four Wistar albino rats were divided into three groups. Cecal incision and suturation was carried out for the experimental model. Intraperitoneally, $3 \mathrm{ml}$ of $0.9 \% \mathrm{NaCl}, 3 \mathrm{ml}$ of PRP, and nothing were applied, and called as saline, PRP, and control groups, respectively. Four subjects in each group were sacrificed at the $3^{\text {rd }}$ and $7^{\text {th }}$ days postoperatively. Adhesion formations and giant cell, lymphocyte/plasmocyte, neutrophil, and histiocyte counts were assessed and hydroxyproline levels were measured in all groups and statistical comparisons were performed.

Results: Except giant cell $3^{\text {rd }}$ day scores, PRP had the lowest adhesion, neutrophil, lymphocyte, plasmocyte, histiocyte and fibrosis scores. Both $3^{\text {rd }}$ and $7^{\text {th }}$ days scores of giant cell, neutrophil, lymphocyte, plasmocyte, but only $7^{\text {th }}$ days scores of histiocyte reaction and fibrosis were statistically significant $(p<0.05)$. Hydroxyproline levels were lower in the saline group at the $3^{\text {rd }}$ day. However, at the $7^{\text {th }}$ day, the levels were lower in the PRP group and no statistically significant difference was found compared to the saline group $3^{\text {rd }}$ day levels $(p>0.05)$.

Conclusions: Platelet-rich plasma has a reducing effect on the postoperative peritoneal adhesions with separation of the damaged tissues, affecting the inflammation, matrix metalloproteinase, plasminogen activation or the other stages of adhesion formation.
\end{abstract}

Key words: peritoneum, postoperative, inflammation, adhesion, formation, platelet-rich plasma.

\section{Introduction}

Postoperative peritoneal adhesions (PPA) are the most common, important, morbid and costly complications of abdominopelvic sur-

\author{
Corresponding author: \\ Dursun Özgür Karakaş \\ Department \\ of General Surgery \\ Okmeydanı Training \\ and Research Hospital \\ Istanbul, Turkey \\ Phone: +90 02122387900 \\ Fax: +90 02122387902 \\ E-mail: \\ drdok1978@hotmail.com
}


gery, with an incidence up to 60-93\%, and these complications are associated with intestinal obstructions, chronic pain and secondary infertility. Local inflammatory reaction with fibrinous exudate and fibrin formation caused by peritoneal trauma are the initial steps of peritoneal adhesions [1-3]. The equilibrium between fibrin deposition and degradation is important so as to determine normal peritoneal healing or formation of PPA. Peritoneal wound healing is regulated by various cytokines, mediators and growth factors $[4,5]$.

Experimental and clinical preventive studies which are required for innovations have commonly been conducted by scientists. Solid, gel or liquid barrier, surgical or non-invasive strategies, cellular strategies, drugs, combination strategies, and also biologic strategies such as activated protein $C$ and neurokinin 1 receptor antagonist have been used to prevent PPA in clinical or experimental studies [6-8].

Platelet-rich plasma (PRP) is an autologous concentration of platelets with various growth factors in concentrated plasma and has been used as a popular biologic treatment method recently for dentistry, orthopedics, dermatology and plastic surgery $[9,10]$. Various growth factors contained in PRP have many effects on inflammation, wound or tissue healing $[11,12]$.

The aim of this study is to reveal the effect of PRP on postoperative peritoneal inflammation and adhesions.

\section{Material and methods}

This study was carried out at the Experimental Animal Laboratory of Uludağ University after the approval of the Animal Ethics Committee had been obtained by the researchers. All protocols were in accordance with the regulations concerning the care and use of laboratory animals as in the Declaration of Helsinki.

\section{Animals}

Twenty-four Wistar albino outbred female rats (mean weight, $250 \pm 30 \mathrm{~g}$, mean age 7 months) were divided into 3 groups [13]. Platelet-rich plasma was obtained from the blood of an additional
4 rats, based on the standard protocol described by Okuda et al. [14]. The supernatant containing the concentrated platelets was used as PRP.

\section{Experimental models}

After isoflurane inhalation anesthesia, rats were laid in a supine position. After abdominal skin preparation, a midline incision was performed. The cecum was pulled out of the abdomen, and a $1 \mathrm{~cm}$ long incision was performed. Stool was seen in the side of the wound and sutured by $3 / 0$ silk one by one. Thereafter, the cecum was returned to the normal position [13].

For the control group (C) none, saline group (S) $3 \mathrm{ml}$ of $0.9 \%$ saline solution, and PRP group $3 \mathrm{ml}$ of PRP solution were instilled intraperitoneally. The midline incision was closed with 4/0 polypropylene running sutures. $100 \mathrm{mg} / \mathrm{kg}$ of paracetamol was injected subcutaneously for analgesia [13].

\section{Parameters}

Four rats from each group were sacrificed at the $3^{\text {rd }}$ and $7^{\text {th }}$ days postoperatively with 100$150 \mathrm{mg} / \mathrm{kg}$ high dose sodium thiopental. The peritoneal cavity was opened through a "reverse U" incision [13]. Subsequently, the anterior abdominal wall, peritoneal cavity, small bowels and cecum were examined carefully and assessed according to the staging scale [15] (Table I). After macroscopic evaluation, a cecal segment with neighboring mesenteric root were resected for both histopathologic and biochemical examination. Sacrificed animals were put into the Uludağ University Experimental Animal Laboratory's medical waste and the study was completed.

Resected cecal specimens were fixed in $10 \%$ formol solution. After histopathologic standard protocols, two slices of $3 \mu \mathrm{m}$ in thickness were prepared by microtome from each specimen. Hematoxylin and eosin were used for assessing giant cell, lymphocyte/plasmocyte, neutrophil, and histiocyte reaction and Masson's trichrome was used for fibrosis [13]. Giant cell, lymphocyte/ plasmocyte, neutrophil, histiocyte reaction and fibrosis were scored from zero to three [16] (Table I).

Table I. Scoring system used for macroscopic and microscopic evaluation [13, 14]

\begin{tabular}{|llc|}
\hline Scores & Macroscopic evaluation & Histopathological evaluation \\
\hline 0 & No adhesions & None \\
\hline 1 & Thin, narrow, easily separable adhesions & Rare \\
\hline 2 & Thick adhesions limited to one area & Mild \\
\hline 3 & Thick, wide adhesions & Severe \\
\hline 4 & Thick, wide adhesions between organs and abdominal wall & - \\
\hline
\end{tabular}


The pathologist in the study group was blinded during the interpretation of the results.

Cecal samples for biochemical assessment were put into dry tubes and taken to the biochemistry laboratory. After biochemical standard protocols for hydroxyproline, hydroxyproline levels were measured with a spectrophotometer [13].

\section{Statistical analysis}

All statistical analyses were performed using a statistical software package (SPSS 16.0). Numerical data were expressed as mean and standard derivation. The Kruskal-Wallis test was used for statistical analysis of giant cell, lymphocyte/ plasmocyte, neutrophil, histiocyte reaction and fibrosis scores as their values were nonparametric, and the number of subjects in each group was lower than 30. Statistical significance of hydroxyproline levels was assessed using the ANOVA test because all values obtained from three groups were parametric [13]. Results were expressed with

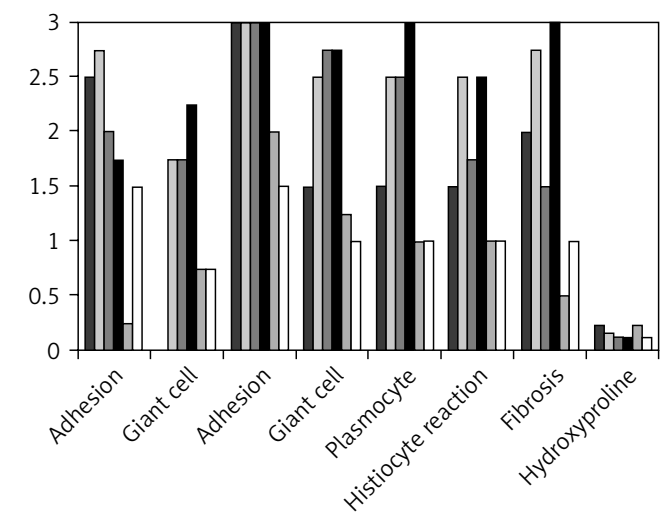

C3 - control $3^{\text {rd }}$ day $\square C 7-$ control $7^{\text {th }}$ day $\square$ S3 - saline $3^{\text {rd }}$ day

D 7 - saline $7^{\text {th }}$ day $\square$ PRP3 - platelet-rich plasma $3^{\text {rd }}$ day $\square$ PRP7 - platelet-rich plasma $7^{\text {th }}$ day results

Figure 1. Graphic image of the results of macroscopic, histopathologic and biochemistry assessment a confidence interval of $95 \%$. $P$-values below 0.05 were considered as statistically significant.

\section{Results}

There was no surgical complication or mortality during the study. The results of our study are shown in Table II and Figure 1. Adhesion scores were $2.5 \pm 0.57$ at the $3^{\text {rd }}$ day, $2.75 \pm 0.95$ at the $7^{\text {th }}$ day in the control group, $2.0 \pm 0.0$ at the $3^{\text {rd }}$ day, $1.75 \pm 0.5$ at the $7^{\text {th }}$ day in the saline group, 0.25 \pm 0.5 at the $3^{\text {rd }}$ day, $1.5 \pm 0.57$ at the $7^{\text {th }}$ day in the PRP group (mean \pm standard derivation). Third and $7^{\text {th }}$ day scores were lower in the PRP group but only $3^{\text {rd }}$ day scores were statistically significant ( $p=0.01, p=0.09$ respectively).

Control group scores were $0.0 \pm 0.0,3.0 \pm 0.0$, $1.5 \pm 0.57,1.5 \pm 0.57,1.5 \pm 0.57,2.0 \pm 1.15$ at the $3^{\text {rd }}$ day, $1.75 \pm 1.5,3.0 \pm 0.0,2.5 \pm 0.57,2.5 \pm 0.57,2.5$ $\pm 0.57,2.75 \pm 0.5$ at the $7^{\text {th }}$ day (mean \pm standard derivation; giant cell, neutrophil, lymphocyte, plasmocyte, histiocyte and fibrosis respectively). Saline group scores were $2.0 \pm 0.0,1.75 \pm 0.5,3.0$ $\pm 0.0,2.75 \pm 0.5,2.5 \pm 0.57,1.75 \pm 0.5,1.75 \pm 0.5$ at the $3^{\text {rd }}$ day, $1.75 \pm 0.5,2.25 \pm 0.95,3.0 \pm 0.0,2.75 \pm 0.5$, $3.0 \pm 0.0,2.5 \pm 0.10,3.0 \pm 0.0$ at the $7^{\text {th }}$ day (mean \pm standard derivation; giant cell, neutrophil, lymphocyte, plasmocyte, histiocyte and fibrosis respectively). Platelet-rich plasma group scores were 0.25 $\pm 0.5,0.75 \pm 0.5,2.0 \pm 0.0,1.25 \pm 0.5,1.0 \pm 0.0,1.0 \pm 0.0$, $0.5 \pm 0.57$ at the $3^{\text {rd }}$ day, $1.5 \pm 0.57,0.75 \pm 0.5$, $1.5 \pm 0.57,1.0 \pm 0.0,1.0 \pm 0.0,1.0 \pm 0.0,1.0 \pm 0.81$ at the $7^{\text {th }}$ day (mean \pm standard derivation; giant cell, neutrophil, lymphocyte, plasmocyte, histiocyte and fibrosis respectively).

Only giant cell $3^{\text {rd }}$ day scores were lower in the control group rather than other scores and all scores were statistically significant $(p=0.012)$. Neutrophil scores were higher and similar in control and saline groups both at the $3^{\text {rd }}$ and the $7^{\text {th }}$ day and statistically significant $(p=0.04, p=0.05$

Table II. Results of macroscopic, histopathologic and biochemistry assessment (mean \pm standard derivation, SD)

\begin{tabular}{|c|c|c|c|c|c|c|c|c|}
\hline \multirow[t]{2}{*}{ Parameter } & \multicolumn{4}{|c|}{$3^{\text {rd }}$ day } & \multicolumn{4}{|c|}{$7^{\text {th }}$ day } \\
\hline & Control & Saline & PRP & $P$-value & Control & Saline & PRP & $P$-value \\
\hline Adhesion score & $2.5 \pm 0.57$ & $2.0 \pm 0.0$ & $0.25 \pm 0.5$ & 0.01 & $2.75 \pm 0.95$ & $1.75 \pm 0.5$ & $1.5 \pm 0.57$ & 0.09 \\
\hline Giant cells & $0.0 \pm 0.0$ & $1.75 \pm 0.5$ & $0.75 \pm 0.5$ & 0.12 & $1.75 \pm 1.5$ & $2.25 \pm 0.95$ & $0.75 \pm 0.5$ & 0.185 \\
\hline Neutrophils & $3.0 \pm 0.0$ & $3.0 \pm 0.0$ & $2.0 \pm 0.0$ & 0.004 & $3.0 \pm 0.0$ & $3.0 \pm 0.0$ & $1.5 \pm 0.57$ & 0.005 \\
\hline Lymphocytes & $1.5 \pm 0.57$ & $2.75 \pm 0.5$ & $1.25 \pm 0.5$ & 0.029 & $2.5 \pm 0.57$ & $2.75 \pm 0.5$ & $1.0 \pm 0.0$ & 0.014 \\
\hline Plasmocytes & $1.5 \pm 0.57$ & $2.5 \pm 0.57$ & $1.0 \pm 0.0$ & 0.019 & $2.5 \pm 0.57$ & $3.0 \pm 0.0$ & $1.0 \pm 0.0$ & 0.009 \\
\hline Histiocytes & $1.5 \pm 0.57$ & $1.75 \pm 0.5$ & $1.0 \pm 0.0$ & 0.111 & $2.5 \pm 0.57$ & $2.5 \pm 0.10$ & $1.0 \pm 0.0$ & 0.037 \\
\hline Fibrosis & $2.0 \pm 1.15$ & $1.5 \pm 1.29$ & $0.5 \pm 0.57$ & 0.167 & $2.75 \pm 0.5$ & $3.0 \pm 0.0$ & $1.0 \pm 0.81$ & 0.011 \\
\hline Hydroxyproline* & $0.239 \pm 0.125$ & $0.13 \pm 0.056$ & $0.227 \pm 0.108$ & 0.295 & $0.154 \pm 0.032$ & $0.128 \pm 0.043$ & $0.122 \pm 0.067$ & 0.65 \\
\hline
\end{tabular}

$P R P$ - platelet-rich plasma, ${ }^{*} \mathrm{mg}$ proline/g protein. 
respectively). Both $3^{\text {rd }}$ and $7^{\text {th }}$ day lower lymphocyte, plasmocyte scores in PRP group were statistically significant $(p<0.05)$. Histiocyte reaction and fibrosis scores were lower in the PRP group both at the $3^{\text {rd }}$ and the $7^{\text {th }}$ day but only $7^{\text {th }}$ day scores were statistically significant $(p=0.037, p=0.011$ respectively).

Hydroxyproline levels were measured as 0.239 $\pm 0.125,0.154 \pm 0.032$ in the control group, 0.13 $\pm 0.056,0.128 \pm 0.043$ in the saline group, 0.227 $\pm 0.108,0.122 \pm 0.067$ in the PRP group (mg proline/g protein \pm standard derivation, $3^{\text {rd }}$ and $7^{\text {th }}$ days respectively).

The difference of hydroxyproline levels were not statistically significant both at the $3^{\text {rd }}$ and $7^{\text {th }}$ days ( $p=0.295, p=0.65$ respectively).

\section{Discussion}

Postoperative peritoneal adhesions are a significant cause of morbidity with $60-70 \%$ of small bowel obstruction, secondary infertility, chronic pelvic pain, requirement of reoperations after abdominopelvic surgery [17]. Postoperative peritoneal adhesions also have major financial implications; e.g. adhesion-related health care costs in the United States were estimated at $\$ 1.3$ billion and in the United Kingdom were estimated at $£ 12$ million [18].

Postoperative peritoneal adhesions start with contacting of injured peritoneal or visceral surfaces after surgery [19]. Vascular permeability increases after peritoneal trauma initially, followed by exudation of inflammatory cells and subsequently formation of fibrin matrix. This matrix is progressively organized and replaced by tissue fibroblasts, macrophages and giant cells. Then, connections occur between injured tissue or peritoneum by modeling fibrin bands. Destruction of fibrin bands by the fibrinolytic system provided peritoneal healing, while reducing the fibrinolytic system results in persistence of fibrin bands at this stage. The fibroblasts deposit extracellular matrix (ECM) containing collagen and fibronectin leading to adhesion formation. Adhesion tissue is formed by macrophages, eosinophils, red blood cells, tissue debris, mast cells and fibroblast mixture [20, 21].

Solid, gel and liquid barriers such as carboxymethyl cellulose + hyaluronic acid, oxide regenere cellulose, and 4\% icodextrin provide adhesion prevention with mechanical separation. Drugs such as anticoagulants, fibrinolytics, thromboxane A2 receptor inhibitors, non-steroid anti-inflammatory drugs, antihistaminics, growth factor inhibitors or modulators, epidermal growth factor or matrix metalloproteinase provide antiadhesive effects with targeting of the steps of adhesion formation [6].

Platelet-rich plasma has been a famous nonsurgical, biologic treatment modality for the last two decades. Tendon, cartilage, bone or joint healing in orthopedics, periodontal or gingival healing in dentistry, and chronic wound healing in dermatology are the most common application sites of PRP. Although not exactly the same, the peritoneal healing mechanism is similar to that of other application areas [9-12, 22].

Platelet-rich plasma shows its effects according to peritoneal adhesion formation stages as described below.

Separation of the damaged peritoneal and visceral surfaces are critical for starting peritoneal healing and subsequent peritoneal adhesion formation. Solid, gel or liquid barriers have been developed primarily for separation of injured surfaces during the 5-7 day required for peritoneal re-epithelialization $[2,6]$. The liquid form of PRP can provide separation of damaged surfaces.

Inflammation is the initial stage of peritoneal adhesion formation [20]. Platelet-rich plasma has an anti-inflammatory effect associated with interleukin 1 (IL-1), IL-6, IL-10 and tumor necrosis factor- $\alpha$ (TNF- $\alpha$ ). These cytokines have an important role in the formation of peritoneal adhesions such as other anti-inflammatory cytokines or growth factors, e.g. hepatocyte growth factor (HGF), IL-8, TGF- $\beta[11,12,23]$.

Tissue plasminogen activator and urokinase-like plasminogen activator are plasminogen activators that convert plasminogen to plasmin that provides degradation of fibrin in the fibrinolytic system [20, 21]. Baeten et al. reported that platelets, especially in platelet-rich plasma, enhanced single chain urokinase type plasminogen activator and increased activation of urokinase type plasminogen activator by serine protease [24].

Matrix metalloproteinases (MMP) are a large family of enzymes that degrade various components of ECM, and are inhibited by tissue-derived inhibitors of matrix metalloproteinase (TIMP). Parietal peritoneum and serosal surface of intraperitoneal organs express MMP and TIMP. Increase in MMP and decrease in TIMP reduce peritoneal adhesions [20, 25]. De Mos et al. reported that PRP showed upregulation of MMP1 and MMP3 [26].

Saline is the most common abdominal cleansing liquid in abdominal surgery and is often used for supplying comparison peritoneal adhesion prevention strategies. Cwalinski et al. reported that normal saline solution may accelerate formation of the peritoneal adhesions [27]. In our study adhesion scores were higher on the $7^{\text {th }}$ day than the $3^{\text {rd }}$ day in both control and PRP groups, but saline groups' scores were lower on the $7^{\text {th }}$ day than the $3^{\text {rd }}$ day. Platelet-rich plasma had lower adhesion scores compared to the other two groups both on the $3^{\text {rd }}$ and $7^{\text {th }}$ days, but it was not statistically significant. Platelet-rich plasma has a pre- 
ventive effect on peritoneal adhesions on both $3^{\text {rd }}$ and $7^{\text {th }}$ days.

Fibrosis score is another indicator of peritoneal adhesions and is the most frequently used parameter to evaluate the effectiveness of adhesion preventive strategies [28]. A low fibrosis score indicates weak adhesions. Our study demonstrated that $3^{\text {rd }}$ day scores were lower than $7^{\text {th }}$ day scores in all groups but $7^{\text {th }}$ day scores were significantly lower in the PRP group. The lowest fibrosis scores of PRP showed that PRP reduced peritoneal adhesions.

Neutrophils are the initial inflammatory cells that occur in the early period of peritoneal healing. Decreasing neutrophils and phagocytosis reduced peritoneal adhesions [28]. In our study the lowest neutrophil scores of the PRP group showed reduced PPA.

Histiocytes are important cells of chronic inflammation and a major component of the monocyte-phagocytic system and tissue consolidating mature macrophages [13]. Macrophages have an important role in adhesion formation related to inflammation and plasminogen activators. Decreased macrophages are associated with adhesion formation [20]. In our study, PRP had the lowest histiocyte scores both on the $3^{\text {rd }}$ and $7^{\text {th }}$ days but only $7^{\text {th }}$ day scores were statistically significant. Platelet-rich plasma decreased adhesion formation in the early and late periods.

Additionally, plasmocytes and lymphocytes play a crucial role in chronic inflammation, triggering the subsequent adhesion maintenance [29]. In our study both plasmocyte/lymphocyte scores were statistically significantly lower in the PRP group both at the $3^{\text {rd }}$ and $7^{\text {th }}$ days. The control group has the most significant difference between $3^{\text {rd }}$ and $7^{\text {th }}$ days. Platelet-rich plasma decreased inflammation and adhesion in early and late periods of adhesion formation.

Giant cells are seen in granulomatous inflammation, which is a different pattern of chronic inflammatory reaction and generally occurs due to foreign bodies [13]. The $3^{\text {rd }}$ day giant cell score was the lowest in the control group but the $7^{\text {th }}$ day score was the lowest in the PRP group. Platelet-rich plasma demonstrated low foreign body reaction during the $7^{\text {th }}$ day.

Hydroxyproline is the basic amino acid of collagen structure [13]. $7^{\text {th }}$ day levels of all groups were lower than $3^{\text {rd }}$ day but a statistically significant difference was not noted. Saline group hydroxyproline levels were lowest at the $3^{\text {rd }}$ day. However, PRP group hydroxyproline levels were lowest at the $7^{\text {th }}$ day. Platelet-rich plasma showed reducing effects in the late period of peritoneal adhesion formation.

In conclusion, PRP were used in orthopedic, craniofacial or dermatological healing with presence of various growth factors but effects on peritoneal healing have not been studied yet. A recent study demonstrated that PRP reduced the postoperative peritoneal adhesions with separation of injured tissues, and affecting inflammation, matrix metalloproteinase, plasminogen activation or the other stages of adhesion formation. Long-term studies are needed to evaluate the further effects of PRP on postoperative peritoneal inflammation and adhesions.

\section{Conflict of interest}

The authors declare no conflict of interest.

\section{References}

1. Buțureanu SA, Buțureanu TA. Pathophysiology of adhesions. Chirurgia 2014; 109: 293-8.

2. Arung W, Meurisse M, Detry O. Pathophysiology and prevention of postoperative peritoneal adhesions. World J Gastroenterol 2011; 17: 4545-53.

3. Moreno-Eutimio M, Espinosa-Monroy L, Orozco-Amaro T, et al. Enhanced healing and anti-inflammatory effects of a carbohydrate polymer with zinc oxide in patients with chronic venous leg ulcers: preliminary results. Arch Med Sci 2018; 14: 336-44.

4. Sartelli M, Griffiths EA, Nestori M. The challenge of post-operative peritonitis after gastrointestinal surgery. Updates Surg 2015; 67: 373-81.

5. Pismensky SV, Kalzhanov ZR, Eliseeva MY, Kosmas IP, Mynbaev OA. Severe inflammatory reaction induced by peritoneal trauma is the key driving mechanism of postoperative adhesion formation. BMC Surg 2011; 11: 30.

6. Ward BC, Panitch A. Abdominal adhesions: current and novel therapies. J Surg Res 2011; 165: 91-111.

7. Dinarvand P, Hassanian SM, Weiler H, Rezaie AR. Intraperitoneal administration of activated protein $C$ prevents postsurgical adhesion band formation. Blood 2015; 125: 1339-48.

8. Reed KL, Fruin AB, Gower AC, Stucchi AF, Leeman SE, Becker JM. A neurokinin 1 receptor antagonist decreases postoperative peritoneal adhesion formation and increasesperitoneal fibrinolytic activity. Proc Natl Acad Sci USA 2004; 101: 9115-20.

9. Marx RE. Platelet-rich plasma (PRP): what is PRP and what is not PRP? Implant Dent 2001; 10: 225-8.

10. Sampson S, Gerhardt M, Mandelbaum B. Platelet rich plasma injection grafts for musculoskeletal injuries: a review. Curr Rev Musculoskelet Med 2008; 1: 165-74.

11. Dhillon RS, Schwarz EM, Maloney MD. Platelet-rich plasma therapy - future or trend? Arthritis Res Ther 2012; 14: 219.

12. Zhang J, Middleton KK, Fu FH, Im HJ, Wang JH. HGF mediates the anti-inflammatory effects of PRP on injured tendons. PLoS One 2013; 8: e67303.

13. Karakas DO, Yigitler C, Gulec B, Kucukodaci Z, Ipcioglu OM, Akin ML. Comparison of $4 \%$ Icodextrin and omega 3 fatty acids in prevention of peritoneal adhesions. Indian J Surg 2014; 76: 181-6.

14. Okuda K, Kawase T, Momose M, et al. Platelet-rich plasma contains high levels of platelet derived growth factors and transforming growth factor- $\beta$ and modulates the proliferation of periodontally related cells in vitro. J Periodontol 2003; 74: 849-57. 
15. Blauer KL, Collins RL. The effect of intra peritoneal progesterone on postoperative adhesion formation in rabbit. Fertil Steril 1988; 49: 144-9.

16. Delaco PA, Stefanetti M, Pressato D, et al. A novel hyaluronan-based gel in laparoscopic adhesion prevention: preclinical evaluation in an animal model. Fertil Steril 1998; 69: 318-23.

17. Ellis H, Moran BJ, Thompson JN, et al. Adeshion-releated hospital readmissions after abdominal and pelvic surgery: a retrospective cohort study. Lancet 1999; 353: 1476-80.

18. Practice Committee of the American Society for Reproductive Medicine. Control and prevention of peritoneal adhesions in gynecologic surgery. Fertil Steril 2006; 86 (5 Suppl 1): S1-5.

19. Haney AF, Doty E. The formation of coalescing peritoneal adhesions requires injury to both contacting peritoneal surfaces. Fertil Steril 1994; 61: 767-75.

20. Cheong YC, Laird SM, Li TC, Shelton JB, Ledger WL, Cooke I. Peritoneal healing and adhesion formation/reformation. Hum Reprod Update 2001; 7: 556-66.

21. Atta HM. Prevention of peritoneal adhesions: a promising role for gene therapy. World I Gastroenterol 2011; 17: 5049-58.

22. Lynch MD, Bashir S. Applications of platelet-rich plasma in dermatology: a critical appraisal of the literature. J Dermatolog Treat 2015; 14: 1-5.

23. Xie X, Zhang C, Tuan RS. Biology of platelet-rich plasma and its clinical application in cartilage repair. Arthritis Res Ther 2014; 16: 204.

24. Baeten KM, Richard MC, Kanse SM, Mutch NJ, Degen JL, Booth NA. Activation of single-chain urokinase-type plasminogen activator by platelet-associated plasminogen: a mechanism for stimulation of fibrinolysis by platelets. J Thromb Haemost 2010; 8: 1313-22.

25. Wright JA, Sharpe-Timms KL. Gonadotropin-releasing hormone agonist therapy reduces postoperative adhesion formation and reformation after adhesiolysis in rat models for adhesion formation and endometriosis. Fertil Steril 1995; 63: 1094-100.

26. de Mos M, van der Windt $A E$, Jahr $\mathrm{H}$, et al. Can platelet-rich plasma enhance tendon repair? A cell culture study. Am J Sports 2008; 36: 1171-8.

27. Cwalinski J, Staniszewski R, Baum E, Jasinski T, Mackowiak B, Bręborowicz A. Normal saline may promote formation of peritoneal adhesions. Int I Clin Exp Med 2015; 8: 8828-34.

28. Vural B, Cantürk NZ, Esen N, et al. The role of neutrophils in the formation of peritoneal adhesions. Hum Reprod 1999; 14: 49-54.

29. Binnebösel M, Rosch R, Junge K, Lynen-Jansen P, Schumpelick V, Klinge U. Macrophage and T-lymphocyte infiltrates in human peritoneal adhesions indicate a chronic inflammatorydisease. World J Surg 2008; 32: 296-304. 